\title{
MODELOS FÍSICOS DO SISTEMA DE CAVALGAMENTO FUNDÃO-CAMBOTAS, NO DOMÍNIO DA ZONA DE CISALHAMENTO DAS CAMBOTAS, QUADRILÁTERO FERRÍFERO, MINAS GERAIS
}

\author{
CAROLINE JANETTE SOUZA GOMES ${ }^{1}$, CARLOS ALBERTO ROSIÈRE ${ }^{2} \&$ MILTON PEREIRA FILHO ${ }^{3}$
}

\begin{abstract}
PHYSICAL MODELS OF THE FUNDÃO-CAMBOTAS FAULT SYSTEM IN THE CAMBOTAS SHERA ZONE DOMAIN, OUADRILÁTERO FERRIFERO, MINAS GERAIS Experiments were undertaken to investigate the structural evolution of the transpressional Cambotas Shear Zone, also known as the Cambotas Fault, which integrates the strongly curved Fundão-Cambotas Thrust System at the eastern portion of the Quadrilatero Ferrifero. The formation of the Cambotas Shear Zone was simulated in three physical models by the translation of a block which was supposed to reproduce the reactivation of preexisting structures, and by the formation of curvatures in fold-thrust belts. An a blo satisfying simulation of the study area. The first domain represents the Falha de Água Quente System, in the eastern extremity of the Quadrilátero Ferrifero, and the second one, the Fundão-Cambotas Thrust System. This de Agua Quente System, in the eastern extremity of the Quadrilatero Ferrifero, and the second one, the Fund the Cambotas Shear Zone as one of its system has been formed under the boundary conditions of a thrust fault with starcase geometry, and the Camps. The Cambotas Shear Zone is characterized by a heterogeneous deformation, with transpression dominated by pure shear in the hinterland as a consequence of the oblique collision between the deformation front and the rigid block of the Caetes Metamorphic Complex in the northern part of the study area. In the foreland, the propagation of the deformation front along the rigid block has produced a transpression dominated by simple shear.
\end{abstract}

Keywords: physical models; Quadrilátero Ferrifero, Fundão-Cambotas Thrust System; Cambotas Shear Zone; transpression; thrust fault with staircase geometry.

RESUMO No presente trabalho estuda-se, através da modelagem física analógica, a evolução estrutural do domínio transpressivo da Zona RESUMO No presente trabalho estuda-se, através da modelagem física analógica, a evolução estrutural do dominio transpressivo da Zona de Cisalhamento das Cambotas, também conhecida como 'Falha das Cambotas', do Sistema de Cavalgamento Fundão-Cambotas. O sistema compõe, de norte a sul, com geome cisalhamento através da reprodução da translação de um pacote de areia, com a reativação de estruturas investiga-se a formaçá da zoma coño oroclinal associado a uma falha de cavalgamento, preexistentes, e atraves da formaça de curvaturas em cinturoes orogenicos. Um sistema oroclinal associado a una 0 primeiro domínio isolada, no domínio distal do antepaís, reproduziu de maneira mais adequada o inventário estrutural da área de estudo. O primeiro domínio estrutural representa o Sistema de Falhas de Água Quente, do extremo leste, e o segundo, o Sistema de Cavalgamento Fundão-Cambotas. Este, se formou sob as condições de contorno de uma falha de empurrão com geometria em degrau, constituindo a Zona de Cisalhamento das Cambotas uma de suas rampas laterais, oblíquas. A Zona de Cisalhamento das Cambotas é caracterizada por uma deformação heterogênea, com Came obliqua entre a frente de deformação e o bloco transpressão dominada por cisalhamento puro, na sua extremidexo Metamórfico Caetés, a norte. No antepaís, a propagação da frente de deformação ao longo do bloco rígido causou uma transpressão dominada por cisalhamento simples.

Palavras-chave: modelos físicos; Quadrilátero Ferrífero; Sistema de Cavalgamento Fundão-Cambotas; Zona de Cisalhamento das Cambotas; transpressão; falha com trajetória em degrau.

INTRODUÇÃO A feição mais notável do Sistema de Cavalgamento Fundäo-Cambotas (SCFC) (Fig. 1), um cinturão de dobras e falhas, na região leste do Quadrilátero Ferrífero $(\mathrm{QF})$, é a sua geometria curva, em planta. Na década de 90 , grande número de autores (Marshak 1988, Marshak \& Wilkerson 1992, Marshak et al. 1992, Marshak \& Flöttmann 1996, Macedo 1997 etc.) têm estudado, a cinemática de cinturões orogênicos com traços regionais sinuosos. Carey (1955) definiu as curvaturas como secundárias ou oroclinais, quando estas nascem retilíneos e evoluem para geometrias curvas, e, primárias, quando estas já nascem com o traçado curvo. As primeiras são relacionáveis a obstáculos no antepaís, que restringem o avanço livre da frente de deformação, à variação lateral na espessura de unidades litológicas, à atuação de falhas transcorrentes, que causam arrasto, ou à superposição de falhas compressivas de diferentes idades, não paralelas.

A maioria dos pesquisadores que trabalha no QF (Chemale Jr. et al. 1991, Renger et al. 1994, Machado et al. 1996, Endo 1997, Alkmim et al. 1998 etc.) admite que as rochas do Supergrupo Minas tenham se depositado em antigas bacias arqueanas que, posteriormente, foram deformadas para megadobras. Os autores concordam também que, no brasiliano, as megadobras sofreram uma inversão tectônica que afetou, especialmente, o domínio leste do QF. Existem controvérsias quanto à idade das megaestruturas, ao sentido do vetor transporte tectônico e ao tectonismo atuante.

Com base nas análises de dados de campo disponíveis e dos diversos modelos tectônicos conceituais apresentados para o QF, pretendese investigar através de modelos físicos a tectônica que gerou a Zona de Cisalhamento das Cambotas (ZCC). Serão discutidas as feições geométricas e cinemáticas da ZCC, concebendo-se a nucleação do SCFC relacionada à translação de um bloco rochoso, reativando estruturas preexistentes (Rosière et al. 1987, Chemale Jr. et al. 1991, Endo 1997) e dentro da ótica de curvaturas de cinturões orogênicos como sugerido em trabalho recente por Hashizume (1998).

\section{CONTEXTO GEÓLOGICO / ESTRUTURAL E TECTÔNICO}

DA ZCC O SCFC, de geometria aproximadamente triangular, é constituído no seu domínio norte por dois segmentos de falhas quase paralelos entre si, de direção NE-SW, a 'Falha das Cambotas' (Crocco Rodrigues et al. 1989) e o braço norte da 'Falha do Fundão' (Dorr 1969). A última se estende para sul através de um segmento N-S e outro, NW-SE, contorna o Anticlinal de Mariana e continua até o interior do Sinclinal D. Bosco. Nesta região se une à 'Falha do Engenho', um sistema de falhas regionais, de direção grosseiramente $\mathrm{E}-\mathrm{W}$ e caráter transcorrente.

Segundo Dorr (1969) e Alkmim et al. (1988), o 'Sistema FundãoCambotas' provavelmente se conecta, em profundidade, a leste, a um sistema imbricado de falhas: as falhas de Ouro Fino, das Flechas, Alegria, Frazão, Água Quente e outras secundárias. A mais extensa destas falhas, a Falha de Âgua Quente ou Sistema de Falhas de Água Quente (SFAQ), de direção aproximadamente N-S, e traçado sinuoso, constitui a borda leste do bloco rochoso limitado pela SCFC. O SFAQ, de vergência para oeste, empurra rochas do embasamento sobre as unidades supracrustais.

No domínio da ZCC, porção norte do SCFC, estão representadas as três principais unidades litoestratigráficas do QF: um complexo metamórfico, o Supergrupo Rio das Velhas e o Supergrupo Minas. Além destes, ocorre, em lascas de empurrão, a leste do complexo metamórfico, o Quartzito Cambotas do Supergrupo Espinhaço.

O Complexo Metamórfico Caetés, a norte da ZCC, é composto por gnaisses graníticos, migmatitos e intrusões graníticas. Idades radiométricas, de $2,7 \mathrm{Ga}$ (Machado et al. 1989), obtidas em um granodiorito, conferem-lhe uma idade mínima relacionável ao Evento Rio das Velhas (Carneiro 1992). Com esta idade, o Complexo Metamórfico Caetés representaria um alto estrutural durante a deposição Minas, mais nova que $2,5 \mathrm{Ga}$ (Machado et al. 1996).

Extensas zonas de cisalhamento dúcteis compressivas, N-S, formam no Complexo Metamórfico Caetés, um sistema de leques de

1 Departamento de Geologia, Escola de Minas, Universidade Federal de Ouro Preto, Morro do Cruzeiro, s/n, 35.400-000 Ouro Preto - Minas Gerais - Brasil, Fax: (031) 559 1605, e-mail: caroline@degeo.ufop.br.

2 CPMTC/IGC - Universidade Federal de Minas Gerais, e-mail: crosiere@oraculo.lcc.ufmg.br

3 Bolsista Iniciação Científica: FAPEMIG - Departamento de Geologia, Escola de Minas, Universidade Federal de Ouro Preto, Morro do Cruzeiro, s/n., 35.400000 Ouro Preto - Minas Gerais - Brasil 

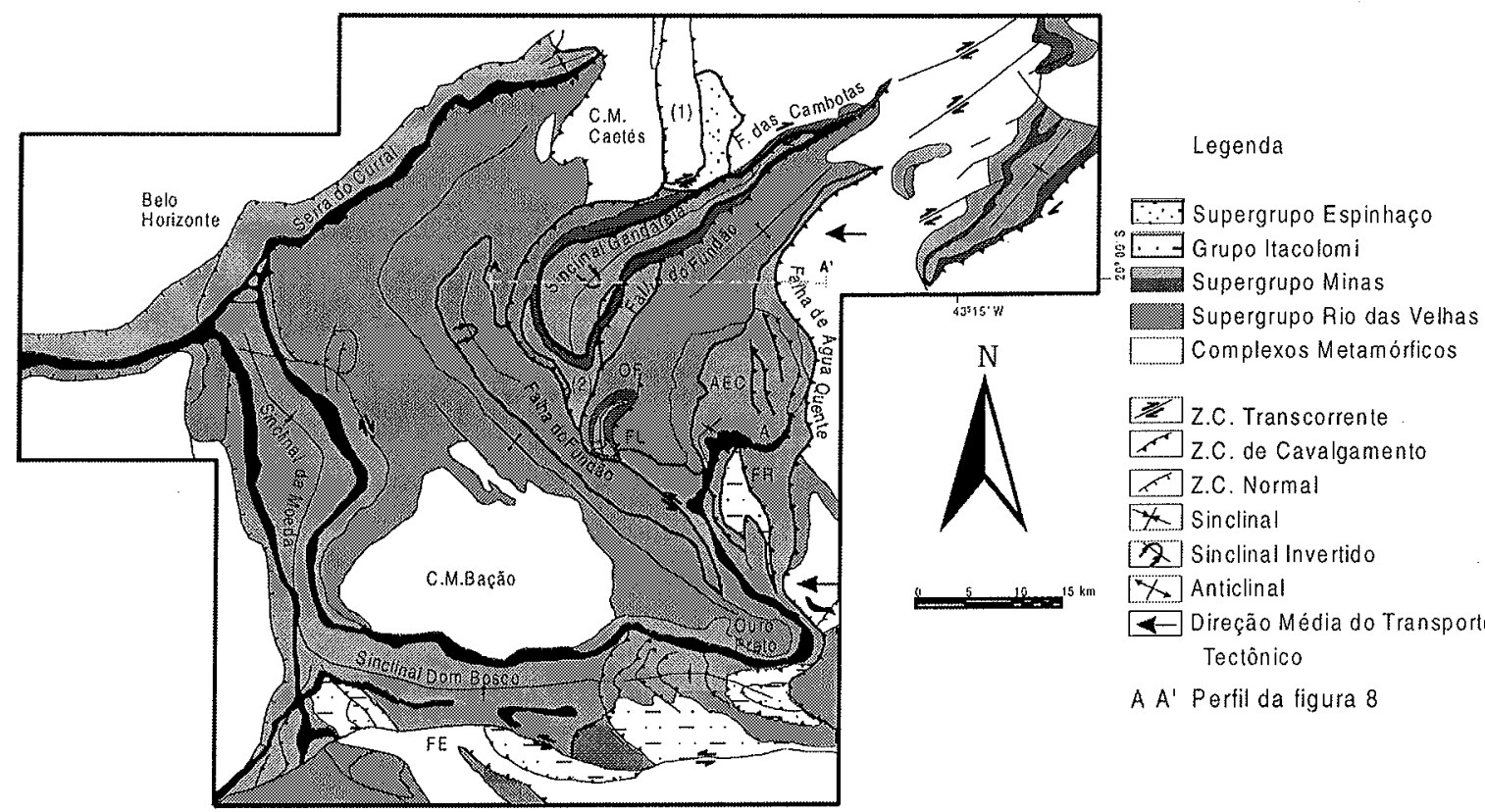

Figura I - Mapa geológico-estrutural do Quadrilátero Ferrífero com representação mais detalhada das estruturas da regiäo leste, do dontínio do Sistema de Cavalgamento Fundão-Cambotas (modificado de Hashizume 1998). (1) Sistema de Cavalgamento Córrego do Garimpo; (2) Sistema de Cavalgamento FundãoCambotas; FE-Falha do Engenho; FR-Falha do Frazão; A- Falha de Alegria; OF-Falha de Ouro Fino; FL-Falha das Flechas; AEC-Alto Estrutural da Serra do Caraça; C.M.Caetés - Complexo Metamórfico Caetés; C.M.Bação - Complexo Metamórfico Baçäo.

empurrão imbricados, com vergência para oeste, o Sistema de Cavalgamento do Córrego do Garimpo (SCCG) (Crocco Rodrigues et al. 1989). A borda sul do complexo é limitada pela ZCC, caracterizada como um transpurrão, que integra o SCFC.

Rosière \& Noce (1987), Endo (1988), Crocco Rodrigues et al. (1989), Fonseca (1990), Endo \& Fonseca (1992), Endo \& Alkmim (1992), Fonseca \& Alkmim (1992) entre outros, efetuaram cuidadosa análise estrutural ao longo de parte das diferentes falhas que compõem o SCFC, concluindo que a 'Falha das Cambotas' assim como a Falha do Fundão (segmento NW-SE) constituem rampas oblíquas. O segmento N-S, da Falha do Fundão, representaria uma rampa frontal.

Costa (1992) descreve na 'Falha das Cambotas' protomilonitos, com foliação milonítica e lineações de estiramento, de baixo ângulo (com máximo em $\mathrm{S} 88^{\circ} \mathrm{E}, 28^{\circ}$ ), confirmando o seu caráter de rampa oblíqua/lateral. Descreve ainda uma coaxialidade entre o SCFC e o Sistema de Cavalgamento Córrego do Garimpo (SCCG), mais a norte, com movimentação de leste para oeste e clara superposição do primeiro sobre o segundo. Este fato já foi sugerido por Crocco Rodrigues et al. (1989) e Chemale Jr. et al. (1991) que observaram que a escama tectônica do Quartzito Cambotas, de estruturação N-S, sofre, na sua borda sul, arrasto para SW. A 'Falha das Cambotas' representaria portanto uma tectônica mais nova ou a expressão tardia de uma deformação progressiva com vetor transporte tectônico de leste para oeste.

Em uma estreita faixa ENE-WSW, entre o Complexo Metamórfico Caetés (CMC) e a aba noroeste do Sinclinal da Gandarela, ocorrem rochas do Grupo Nova Lima, do Supergrupo Rio das Velhas, xistos, metabásicas e formação ferrífera. Hashizume (1998) descreve, no nordeste do Sinclinal da Gandarela, microestruturas miloníticas nos xistos desta unidade.

As rochas do Supergrupo Minas ocorrem no Sinclinal da Gandarela que, segundo Rosière et al. (1987) constitui uma estrutura alóctone. O Sinclinal da Gandarela, na região norte do SCFC, representa uma grande dobra inversa com vergência para NW e direção $N 60^{\circ} \mathrm{E}$ que passa a $N 40^{\circ} \mathrm{E}$, e, no extremo sul, a N-S (Rosière et al. 1991). Os flancos desta dobra dispõem-se paralelamente à 'Falha das Cambotas' (flanco normal, NW) è à Falha do Fundão (flanco inverso, SE) (Fig. 1). O contorno estrutural do sinclinal é definido pelo bandamento composicional primário, paralelo à uma foliação metamórfica com feições miloníticas.

Para Chemale Jr. et al. (1991) a tectônica brasiliana teria deslocado e deformado o Sinclinal da Gandarela através do SCFC, em um evento compressivo com deslocamento de leste para oeste.

Em 1997, Endo propõe para o QF um modelo tectônico que difere de todos os anteriores pelo processo deformacional, transpressivo com direção de fluxo N-S. Segundo o autor, a nucleação do SCFC estaria relacionado ao segundo megaevento transpressivo, sinistral, do Ciclo Orogênico Transamazônico (Orogênese Itacolomi), com deslocamento tectônico regional para NW e, localmente, para NNW e WNW. O autor descreve ainda uma reativação de descontinuidades preexistentes, no Brasiliano (Orogênese Brasiliana I), com transporte tectônico de leste para oeste.

Alkmim \& Marshak (1998) relacionam a formação do SCFC a um cinturão de dobras e falhas transamazônico. No brasiliano, o cinturão do leste do $\mathrm{QF}$, teria sofrido uma reativação com vetor transporte dirigido para oeste.

Hashizume (1998) sugere para a geometria convexa, para oeste, do SCFC, uma estrutura do tipo oroclinal. Esta teria sido produzida pelo confinamento do sistema de empurrões por altos estruturais representados pelos complexos metamórficos de Caetés, a norte, e do Bação, a sul.

PROCEDIMENTO EXPERIMENTAL Em três séries de experimentos (ZCC-I: a e b, ZCC-II: a e b e ZCC-III) investigou-se a evolução tectônica da ZCC, em um domínio estrutural que compreende o alto estrutural do $\mathrm{CMC}$, a norte, e as rochas supracrustais de parte do SCFC, a sul.

As modelagens da série ZCC-I visaram reproduzir, de maneira simplificada, uma reativação do SCFC, previamente nucleado, o que implicava na translação de um bloco alóctone (conforme Rosière et al. 1987), enquanto as séries ZCC-II e ZCC-III simularam a sua formação relacionada a uma tectônica compressiva do tipo oroclinal.

Em todos os experimentos assumiu-se um vetor transporte tectônico, médio, de leste para oeste. Os modelos foram desenvolvidos em caixas de experimentos transparentes, de 20 (30) cm de largura, de $43,5 \mathrm{~cm}$ de comprimento máximo e de $10 \mathrm{~cm}$ de altura.

Foram respeitados os preceitos teóricos da modelagem física analógica conforme estabelecidas por Hubbert (1937), primeiramente aplicados por McClay \& Ellis (1987a, b) e Vendeville et al. (1987) e descritos em Gomes et al. (1999).

Não houve preocupação com o nível crustal no qual ocorreu a compressão uma vez que o objetivo do trabalho era analisar o processo deformativo. Assim, utilizaram-se como materiais equivalentes, a areia seca, colorida artificialmente, de propriedades rúpteis, e, em alguns experimentos, camadas de cristais de mica, para simular o efeito de camadas incompetentes entre níveis mais rígidos ou então, de uma alta pressão dos poros em zonas de cisalhamento. $O$ coeficiente de atrito na base do modelo foi alterado revestindo-se o fundo da caixa com filme plástico ou papel lixa de madeira (A237-80). Adotou-se uma escala de $1: 100.000$ de maneira que a coluna de areia de $5 \mathrm{~cm}$ de altura, usada 
nos experimentos, representava $5 \mathrm{~km}$ de espessura de crosta, na natureza.

Nos dois modelos da primeira série (ZCC-Ia e ZCC-Ib) simulou-se uma zona de transpressão com reativação de estruturas preexistentes, de direção $\mathrm{N} 60^{\circ} \mathrm{E}$ (Fig. 2). Os modelos se diferenciavam entre si pelo material utilizado para representar o CMC: um bloco de isopor simulando um corpo rígido em ZCC-Ia, que foi substituído por areia pura em ZCC-Ib. No primeiro caso visava-se representar o CMC como um alto estrutural do embasamento com comportamento mais rígido comparado com aquele das supracrustais e, no segundo, pretendia-se simular simplesmente a crosta rúptil de propriedades mecânicas homogêneas, com zonas de fraqueza preexistentes. Em ambos os experimentos um pacote de areia, representando o bloco alóctone do domínio da $S C F C$, foi montado sobre uma fina placa de metal (PF, na figura 2, primeiro desenho) conectada à parede frontal móvel da caixa de experimento. Desta maneira, reproduziu-se a translação de um bloco rígido sobre um descolamento basal, com transpressão lateral.

Nos experimentos da série II (Fig. 2) modelou-se a ZCC como parte de um sistema de cavalgamento em estilo oroclinal. O CMC, que representa um dos obstáculos no antepaís, foi simulado por um bloco rígido, de isopor. No lugar do segundo obstáculo, o Complexo Metamórfico Bação (CMB), a sudoeste, utilizou-se a própria parede lateral da caixa de experimento, uma vez que não era objetivo do trabalho abranger o domínio estrutural do SCFC, como um todo. Nesta série de experimentos, o descolamento basal é representado pela própria base da caixa, revestida de um filme plástico, de baixo coeficiente de atrito. Variou-se nos modelos $a$ e $b$ a forma do encurtamento. Em ZCC-IIa, modelou-se uma compressão afetando conjuntamente o
CMC e o domínio estrutural sul, simulando uma única fase deformativa, enquanto, em ZCC-IIb, a deformação atuou em duas fases distintas, primeiramente sobre o domínio sul e depois sobre o CMC, o domínio norte. Neste experimento utilizou-se uma caixa de experimentos com duas paredes frontais móveis.

O experimento ZCC-III (Fig. 2) simulou também um sistema de cavalgamento em estilo oroclinal mas com pequenas modificações nas condições de contorno do modelo, que visavam induzir a uma deformação heterogênea: um revestimento com papel lixa que aumentou o coeficiente de atrito no descolamento basal e uma camada de mica no interior do pacote de areia reproduzindo uma litologia incompetente intercalada. Durante o processo de cavalgamento, na natureza, pode ocorrer uma variação na pressão dos fluidos ao longo do descolamento. Uma diminuição no volume de água causa uma resistência cada vez maior ao deslocamento ao longo do plano da falha mestra (Rubey \& Hubbert 1959, Smith \& Wiltschko 1996), causando a transferência do movimento para um horizonte de mais fácil deslizamento.

Modelagens anteriores já demonstraram os efeitos do aumento do atrito na base da caixa do experimento e da intercalação de camadas incompetentes (Gomes et al. 1999). Referidas condições de contorno causam uma diminuição no número de empurrões durante o processo de encurtamento e conduzem à formação de uma falha de empurrão com trajetória em degrau. Esta falha se caracteriza por uma rampa unindo o descolamento basal à camada incompetente, no interior do pacote, onde se forma o segundo segmento horizontal do empurrão. Uma nova rampa só se forma se a frente de deformação é induzida a subir a estratigrafia pela presença de algum obstáculo no antepaís.
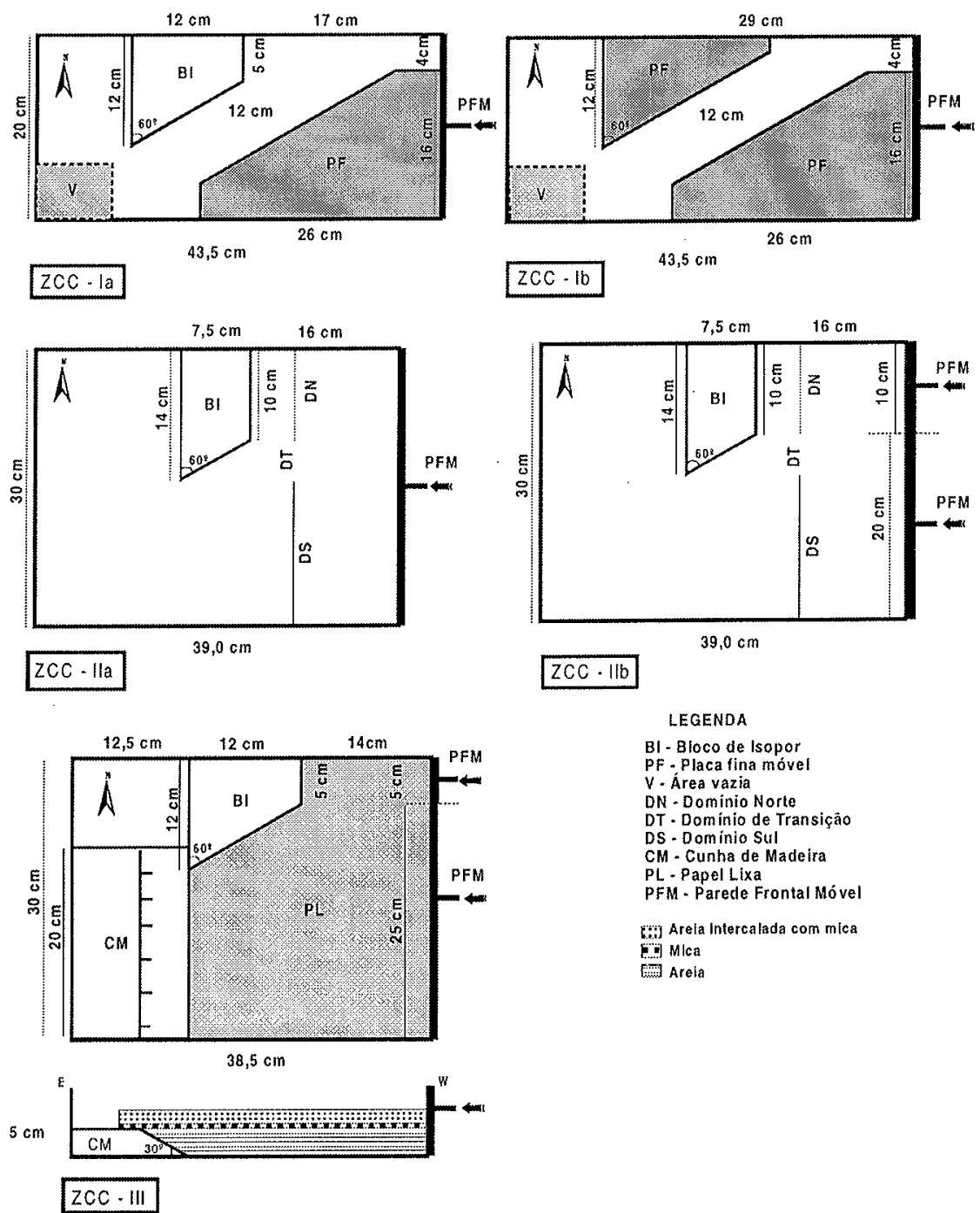

LEGENDA

BI- Bloco de Isopor PF. Placa fina
$V$. Area vazia

DN-Dominio Norte

DT - Dominio de Transiçăo

DS - Dominio Sul

CM - Cunha de Madeira

PL - Papel Lixa

PFM - Parede Frontal Móve

(iij) Arefa intercalada com mica

Di] Mlca

Oivein

Figura 2 - Desenhos esquemáticos, em planta, das três séries de experimentos com respectivas condiçóes de contorno. Apenas o modelo ZCCIII é acompanhado por um corte, E-W, para mostrar a disposiç̧̃o do material analógico sobre a cunha. 

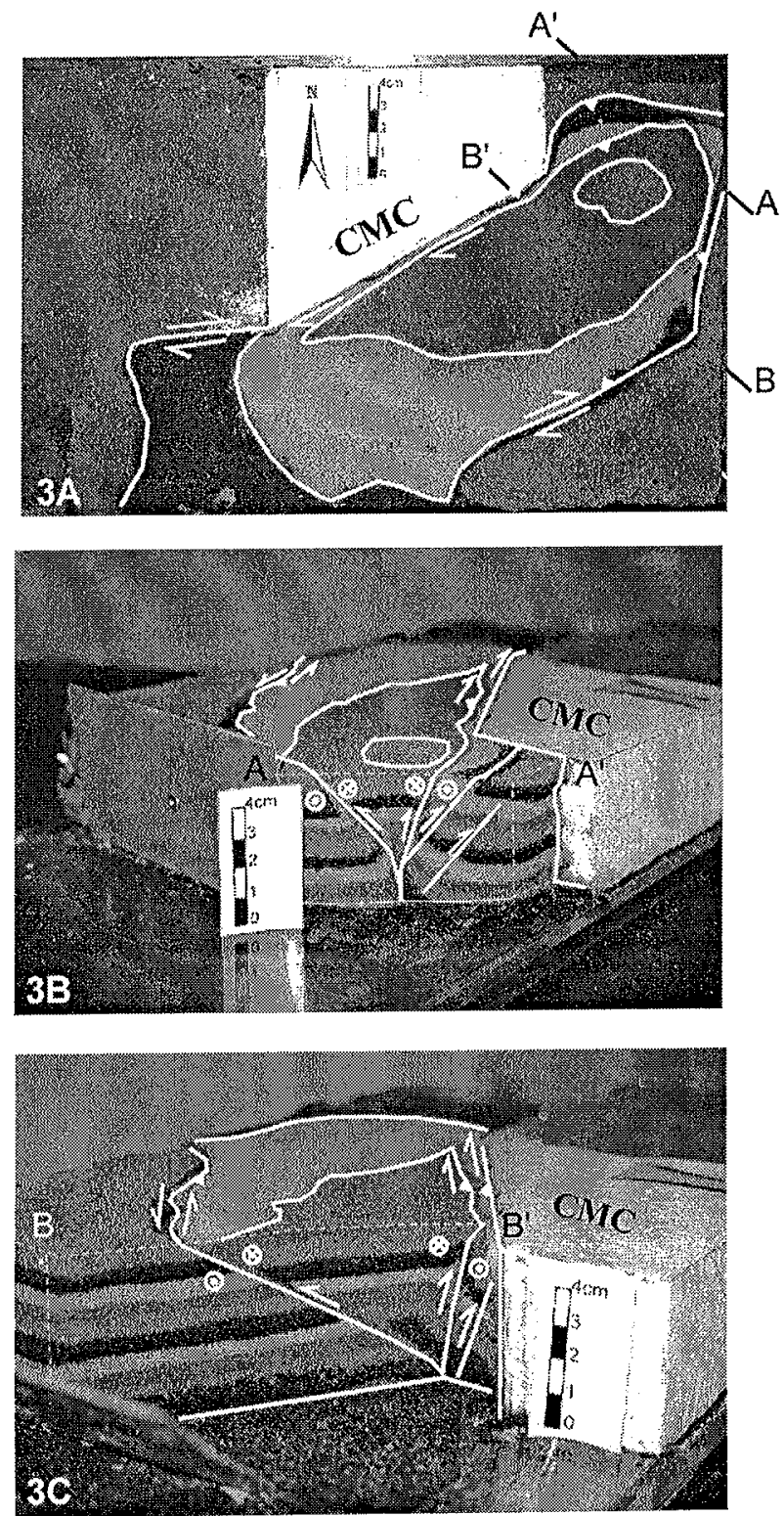

Figura 3 - Fotografias do modelo ZCC-Ia - encurtamento de $26 \%(8 \mathrm{~cm})$. ACorte horizontal (na cota $5 \mathrm{~cm}$, a altura do $C M C$ no modelo) mostrando as linhas de contorno envolvendo parcialmente o bloco do $C M C$. $A A^{\prime}$ e $B B^{\prime}$ ' $r e-$ presentan seç̃es normais à transcorrência principal. B-Perfil AA' revela estrutura em flor positiva. Notar a posição subvertical da principal falha direcional (obliqua), no domínio norte, que ocorre associada a empurróes (obliquos) secundários. C- Perfil BB', a sul do $C M C$, com duas falhas no dominio norte, ambas verticais, caracterizando uma flor positiva assimétrica. CMC-Complexo Metamórfico Caetés.

DESCRIÇ̃̃O DOS EXPERIMENTOS Ambos os modelos da série ZCC-I (Figs. 3 e 4) desenvolveram, após $26 \%$ de encurtamento $(8 \mathrm{~cm})$, uma zona transpressiva ao longo da borda sul do CMC. Esta é caracterizada por dois cavalgamentos com vergência oposta configurando uma estrutura em flor positiva.

No modelo ZCC-Ia (com o CMC, de isopor) as linhas de contorno das camadas, de morfologia elíptica e em círculo (Fig. 3A, corte horizontal), revelam uma ascensão do material analógico mais forte no domínio nordeste da zona em estudo. Além disto, as linhas indicam um envolvimento da estrutura em torno do CMC. Os dois perfis AA' e $\mathrm{BB}^{\prime}$, normais à direção da zona transpressiva (Figs. $3 \mathrm{~B}$ e $3 \mathrm{C}$ ), mostram a estrutura em flor positiva, com padrão assimétrico. Na figura $3 \mathrm{~B}$ observam-se dois empurrões secundários que, associados à falha direcional principal, acomodam a ascensão do material, particularmente alto neste domínio. As duas falhas secundárias se formaram em decorrência da aproximação do bloco alóctone ao CMC produzindo localmente uma deformação do tipo cisalhamento puro. Na borda sul do bloco do CMC as falhas são verticais (Fig. 3C) atuando como estrutu-
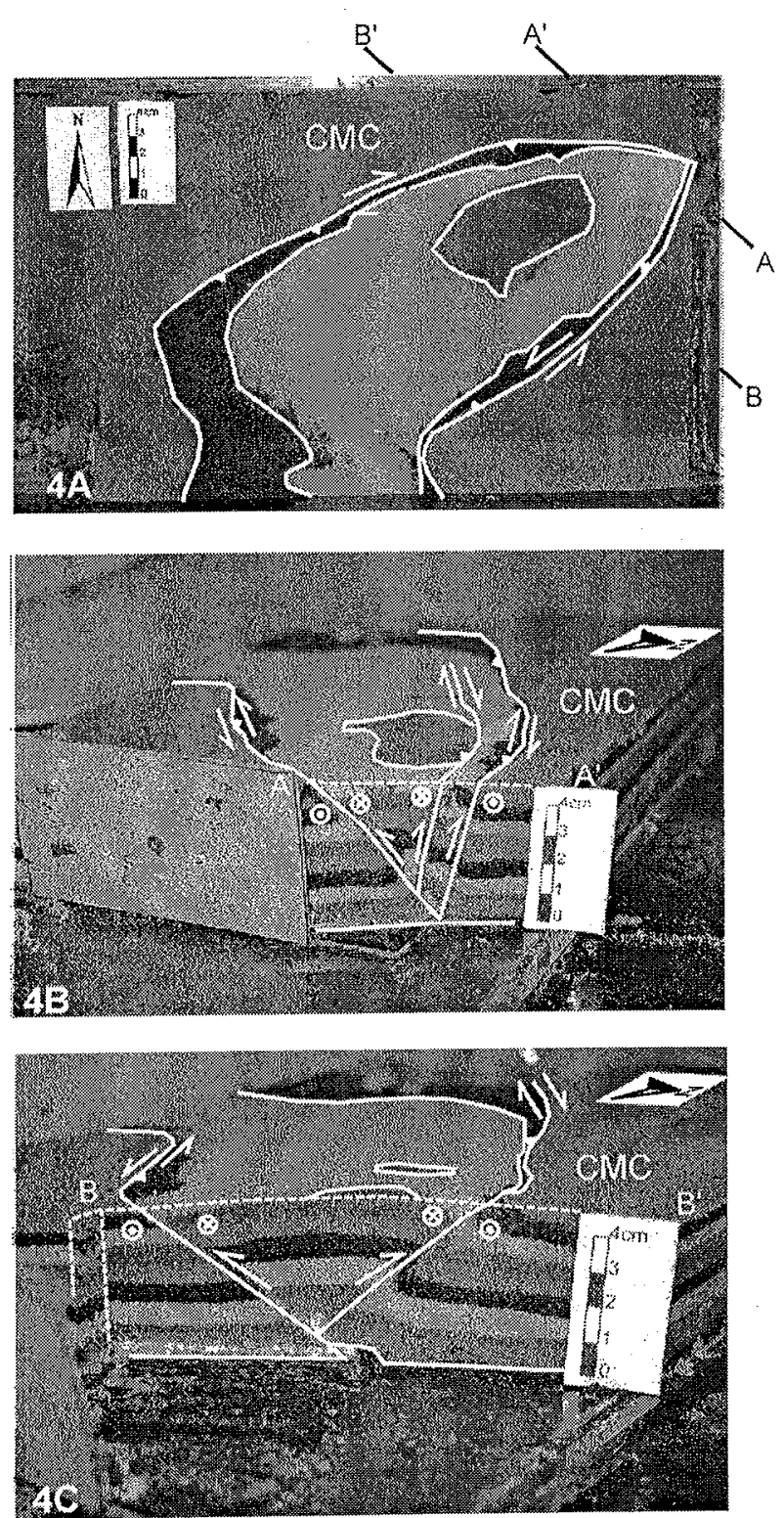

Figure 4 - Fotografias do modelo ZCC-Ib - encurtamento de $26 \%(8 \mathrm{~cm})$. A Corte horizontal (na cota $5 \mathrm{~cm}$ ). $A A^{\prime}$ e $B B^{\prime}$ representam seçöes normais à transcorrência principal. $B$ - Perfil $A A^{\prime}$, paralelo ao perfil $A A^{\prime}$ da figura $3 B$, revela uma estrutura em flor com padrão levemente assimétrico. $C$ - Perfil $B B^{\prime}$, mostra estrutura en flor a sul do CMC, simétrica. CMC - Complexo Metamórfico Caetés.

ras direcionais com baixa componente oblíqua. No domínio sul se forma uma falha com características semelhantes mas com baixo ângulo de mergulho e vergência para sul.

Uma forte ejeção do material analógico na porção nordeste da zona transpressiva também é observada no modelo ZCC-Ib (sem o CMC, de isopor) (Fig. 4A). Não ocorre o arrasto das linhas de contorno das camadas posto que o bloco do CMC, de isopor, foi substituído por um pacote de areia sobre uma placa de metal (Fig. 2). A ascensão do material, no domínio nordeste, é causada quando a frente de deformação encontra a zona de fraqueza preexistente (a placa de metal) produzindo, também, localmente uma deformação do tipo cisalhamento puro. Esta passa progressivamente a um cisalhamento simples com uma pequena componente compressiva. Outra falha, com vergência oposta, se forma na porção sul (Figs. 4B e C).

Os modelos ZCC-II (Figs. 5 e 6) caracterizam o desenvolvimento de um sistema de empurrões que avança ao antepaís e passa além do limite oeste do bloco do CMC. Em planta, as falhas, que ocupam todo o domínio sul da caixa de experimento, possuem traços originalmente retos (não mostrado nas fotografias) que se tornam progressivamente curvos em função da presença dos obstáculos laterais (Figs. $5 \mathrm{~A}$ e B; Figs. 6A, B e C). 

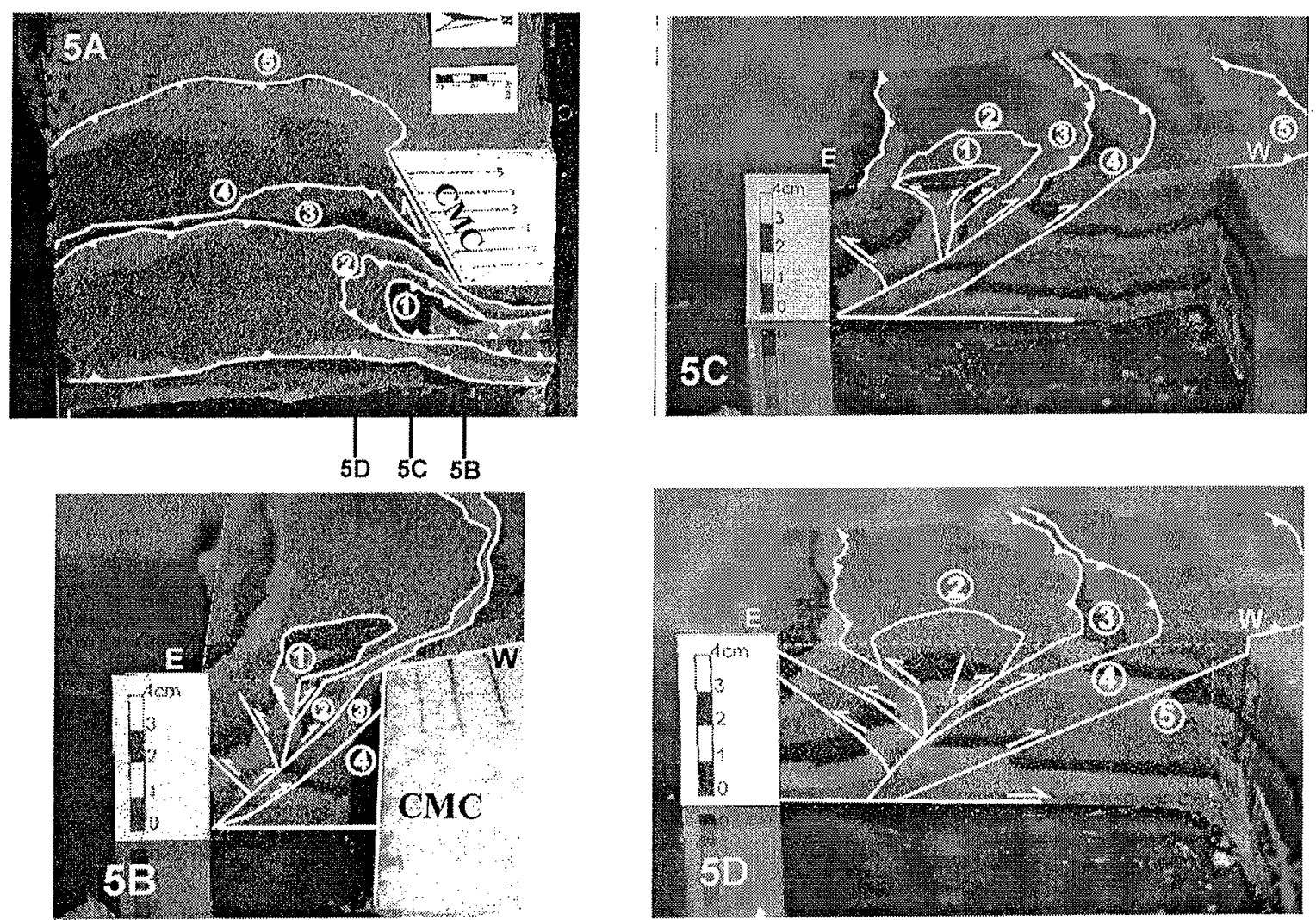

Figura 5 - Modelo ZCC-IIa, que simula o encurtamento em uma única fase, após $26 \%$ (10cm) de deformação. A-Corte horizontal, na altura do CMC, mostra um sistema de empurrões e retroempurrões no dominio norte, que invade o dominio sul. B-Seção vertical do sistema de falhas, no domínio norte, a leste do bloco do CMC. Observar a forte rotação anti-horária destas falhas. C-Seção vertical do sistema de falhas, no domínio de transição e $D-n o$ domínio sull. Os números, de la 5 , indicam a ordem de formação das falhas. A posição das seções verticais das figuras $5 B, C$ e D está representada em $5 A$. CMC-Complexo Metamórfico Caetés.

No modelo ZCC-IIa, que simula a deformação em uma única fase (parede móvel única), o domínio norte sofre um encurtamento relativo maior do que o sul (Fig. 5A) devido à presença do bloco do CMC. No domínio norte ocorre uma forte ejeção do material analógico na vertical e no sentido do transporte tectônico. Sob alta magnitude de deformação, o material tanto transpõe o bloco de isopor quanto é ejetado para sul onde é forçado a contornar o obstáculo.

A seqüência das fotografias $5 \mathrm{~B}, \mathrm{C}$ e D mostra três cortes verticais, de direção $\mathrm{E}-\mathrm{W}$, efetuados de norte para sul. Na figura $5 \mathrm{~B}$ observa-se que os empurrões mais antigos, falhas 1,2 (e 3), a leste do CMC, foram verticalizados em função de sua proximidade com o bloco de isopor. As fotografias das figuras $5 \mathrm{C}$ e D revelam que a medida que se sai do domínio do CMC, desaparece o efeito da rotação anti-horária das falhas, e os empurrões mais novos, de baixo ângulo de mergulho (falhas 4 e 5), afloram a uma distancia maior. Consequentemente, o arrasto das linhas de contorno das camadas de areia, decorre da variação do ângulo de mergulho das falhas de empurrão.

No modelo ZCC-IIb, que reproduz duas fases deformacionais, a primeira no domínio sul, são geradas falhas de empurrão de direção $\mathrm{N}$ $\mathrm{S}$, e, no domínio de transição (Fig. 2), falhas E-W. Estas possuem uma expressiva componente compressiva, que acomodam uma ascensão do material, no sentido vertical e para norte (Fig. 6A).

A segunda fase de deformação, atuante no domínio norte, forma empurrōes com vergência para oeste com concomitante 'rasgamento' das estruturas já existentes. A foto da figura $6 \mathrm{~B}$ mostra, em um corte horizontal (acima da cota do bloco de isopor), a zona de transcorrência com uma terminação em rabo de cavalo. Esta estruturação é produzida pelo avanço livre do material sobre o $\mathrm{CMC}$ e desaparece em cotas mais baixas (Fig. 6C).

Em ambos os modelos da série ZCC-II, o encurtamento ao longo da borda sul do bloco do CMC, é acomodado através de um movimento direcional, caracterizando um processo de transpressão, com forte componente reversa na sua extensão nordeste.

O modelo ZCC-III (encurtamento total de $21 \%$, ou $8 \mathrm{~cm}$ ), no qual a primeira fase de encurtamento se processou no domínio norte, gerou estruturas que, em seus traços gerais, melhor representam o domínio estrutural da ZCC, a norte do SCFC. O processo de encurtamento se inicia com a formação de três falhas de empurrão, por propagação "piggy back", com traço aproximadamente reto em planta (Fig. 7A). Com a deformação progressiva a resistência ao deslocamento da frente de deformação, sobre o descolamento basal, cresce, o que aumenta o rejeito sobre as falhas previamente formadas e a altura da cunha em deformação. Apesar da resistência ao movimento, o encurtamento contínuo gera uma quarta falha de empurrão no antepaís que se propaga, no entanto, apenas até a camada incompetente de mica, no interior do pacote. A partir deste momento, o encurtamento se processa inteiramente sobre a camada incompetente caracterizando, em profundidade, uma falha com trajetória em degrau (Fig. 7B). Em consequêência, observa-se, em planta, um sistema de falhas de empurrão no pós-país e o deslocamento no antepaís é detectado pela translação do pacote em relação a uma linha de referência (LR), desenhada sobre a parede de vidro lateral da caixa de experimentos (Figs. 7A e B).

Os cortes horizontais e verticais demonstram que no modelo $\mathrm{ZCC}$ III ocorreram feições similares àquelas descritas para o modelo ZCCIIb, onde uma zona transpressiva é caracterizada por falhas direcionais com forte componente reversa. Os cortes neste modelo revelam, ao longo da ZCC, de sudoeste para nordeste, três domínios estruturais: $\mathrm{D}_{1}$ transcorrência com leve ascensão de material (Fig. 7D); $\mathrm{D}_{1}$ transcorrência com forte ejeção de material na vertical (Fig. $7 \mathrm{C}$, de cota mais alta do que aquela da figura 7D) e $\mathrm{D}_{\text {- }}$ - partição da deformação, com transcorrência e falhas de empurrão (Figs. 7E e 7F). Os perfis consecutivos N-S das figuras 7E e 7F, expõem o sistema de falhas de empurrão com vergência para norte associado à zona de cisalhamento direcional, na sua extremidade nordeste (no pós-país do bloco do CMC). Neste domínio, a ausência do bloco rígido do CMC impede a formação do movimento oblíquo, causando uma partição da deformação transpressional.

DISCUSSÃo Para a discussão dos resultados, abaixo, relativas a cada uma das três séries de experimentos, fez-se necessário extrapolar os limites da área de trabalho, da ZCC para o âmbito regional do SCFC. 

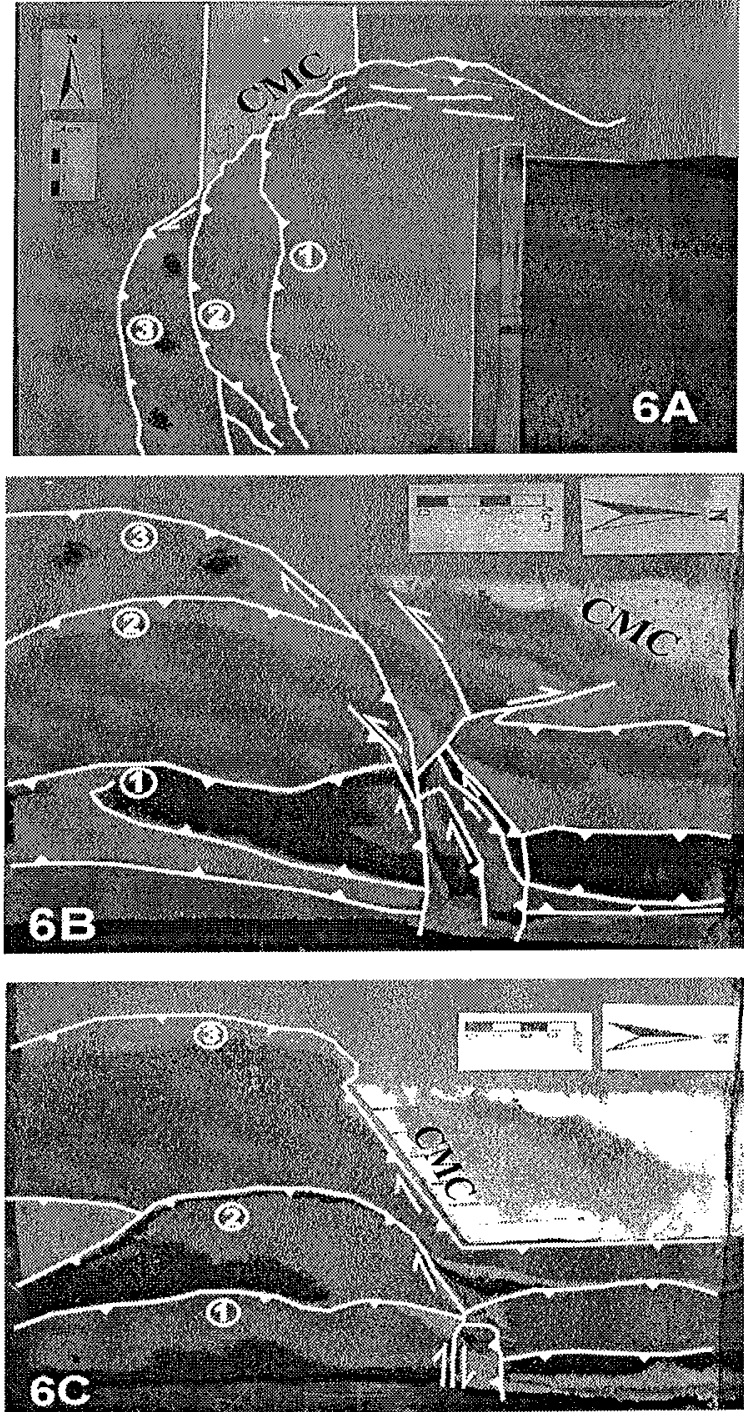

Figura 6 - Cortes horizontais do experimento ZCC-IIb, que simula a deformacão en duas fases tectônicas, após $26 \%(10 \mathrm{~cm})$ de encurtamento. A-Configuracão estrutural do modelo após a primeira fase de encurtamento do domínio sul. B-Conte horizontal efetuado acima do bloco de isopor revelando os empurróes nos domínios sul e norte e uma complexa zona de transcorrência com ejeção de material e terminação em rabo de cavalo, na zona de transição. $C$ Corte horizontal, na altura do bloco do $C M C$, mostrando novamente a complexa zona de transcorrência e a curvatura dos empurröes, no domínio sul observar os enpuroões que avançam além do bloco do CMC (para oeste).

A reprodução, na série de experimentos ZCC-I, da translação de um bloco alóctone, de geometria aproximadamente triangular, delimitado pelo SCFC e pelo SFAQ, como imaginado por autores como Rosière et al. (1987) e Chemale Jr. et al. (1991), requer a acomodação do movimento através de um sistema de estruturas do tipo flor positiva de cinemática transpressiva. Uma cinemática transpressiva foi descrita por Crocco Rodrigues et al. (1989) ao caracterizar a ZCC como um 'transpurrão'. No entanto, zonas de cisalhamento com vergência para sudeste não tem sido registradas no campo até o presente momento. Desta forma, o modelo ZCC-I foi, em princípio, descartado para a evolução da zona de cisalhamento em estudo.

Os modelos da série ZCC-II simularam a formação de um sistema de cavalgamento em estilo oroclinal, pela introdução do bloco do CMC na região norte do experimento e à atuação da parede de vidro, a sul. No domínio sul dos modelos, a configuração dos traços das falhas de empurrão, curvos, que avançam para oeste, se assemelha muito pouco com o respectivo domínio no mapa geológico (Fig. 1). Os empurrões, no interior da área triangular delimitada pelo SCFC, se dispõe, com exceção do domínio do Alto Estrutural da Serra do Caraça, normalmente, paralelas a contatos de unidades. Não se observam, no mapa geológico, traços de falhas curvos cortando, de norte a sul, as unidades dos supergrupos Rio das Velhas e Minas, feição que caracterizaria um sistema de cavalgamento em estilo oroclinal.

A análise conjunta dos modelos ZCC-IIa e IIb revela um arrasto das linhas de contorno das camadas, em planta, quando uma única fase de encurtamento afeta o domínio da ZCC (modelo ZCC-IIa, Fig. 5A). No entanto, neste caso, a zona de transpressão se desenvolve apenas ao longo do limite sul do $\mathrm{CMC}$ com pequena extensão para nordeste. Ao contrário, no experimento ZCC-Ilb, as feições compressivas da transcorrência, vergentes para norte e noroeste, são mais fortes ao longo da extremidade nordeste da zona de cisalhamento do que ao sul do CMC (Figs. 6B e C).

Os processos deformacionais descritos para os modelos ZCC-II e ZCC-III revelam no início do encurtamento a formação de um sistema retilíneo de falhas de empurrão como já descrito em modelos físicos por Mulugeta \& Koji (1987) e Huiqi et al. (1992). Após a frente de deformação sofrer a influência do bloco do CMC sucedem mudanças no processo de encurtamento com a formação de feições transpressivas na ZCC. Uma transpressão dominada por cisalhamento puro pode ser caracterizada em todo o domínio nordeste da zona de cisalhamento, com partição da deformação no pós-país do CMC. No domínio da colisão com o obstáculo ocorre forte ascensão do material analógico com eixo de maior alongamento, subvertical (Fossen et al. 1994). Em função do baixo ângulo entre o vetor transporte tectônico e a borda sul do $\mathrm{CMC}$, de $30^{\circ}$ (Fig. 1), a propagação da ZCC, para sudoeste, acontece através de uma transpressão dominada por cisalhamento simples. Esta é caracterizada por falhas direcionais oblíquas, com decrescente componente reversa.

Em ZCC-III, o papel lixa na base do modelo e a camada incompetente no interior do pacote, retardam o processo de geração e afloramento de novas falhas no antepaís. Neste experimento observase o encurvamento dos traços do sistema de falhas de empurrão, gerados originalmente com geometria retilínea. A falha transcorrente que se forma na borda sul do CMC exerce um efeito acentuado, mas apenas local, sobre a curvatura dos traços das falhas. Isto acontece porque, quando a transcorrência se forma, a frente de deformação já avança, comprimida lateralmente, entre os dois obstáculos (o bloco do CMC, a norte, e a parede lateral sul da caixa de experimentos).

A crescente resistência ao deslocamento na base da caixa do experimento ZCC-III impede a continuação normal da deformação: de nucleação, propagação e emergência de novos empurrões no antepaís. Em substituição aos referidos processos, o encurtamento é acomodado, em profundidade, sobre rampa e patamar de uma falha com geometria em degrau que aflora, no antepaís distal, a uma distância desproporcionalmente grande em relação ao sistema de falhas principal.

Segundo Gomes et al. (1999), a formação de uma falha com trajetória em degrau, em modelos físicos, obedece a uma relação crítica entre os coeficientes de atrito do descolamento basal $\left(\mu_{1}\right)$ e de uma camada incompetente $\left(\mu_{2}\right)$ no interior do pacote. Esta relação pode ser expressa como:

$$
\mu_{1} / \mu_{2} \gg 1
$$

Outro fator que pode bloquear o processo progressivo, normal, de falhamento por propagação "piggy back" seria a presença de obstáculos no antepaís (Gomes \& Ferreira 2000) relacionados ou não a um inventário estrutural preexistente.

No modelo ZCC-III mostrou-se apenas a formação de uma falha simples com trajetória em degrau, em profundidade. Um novo degrau na falha mestra poderia ser gerado se as condições da equação [1], entre o patamar do primeiro degrau e uma segunda camada incompetente, se repetissem, ou, então, na presença de estruturas preexistentes.

Para o domínio do SCFC é possível imaginar que a configuração estrutural pré-brasiliana (o inventário estrutural da Bacia Minas) representou um obstáculo ao transporte livre de lascas de empurrão de leste para oeste, causando a formação de degraus na trajetória de uma ou mais falhas. Propõe-se, assim, para a geometria do SCFC, em profundidade, uma trajetória em degrau, conectada, no pós-país, a um sistema de falhas de empurrão (Fig. 8). Este estaria representado pelo conjunto de falhas que compõe o SFAQ. Para o SCFC, a oeste, o modelo ZCC-III confirma a proposta de Endo (1988), Crocco Rodrigues et al. (1989), Fonseca (1990), Endo \& Fonseca (1992) que preconizam um sistema constituído por uma rampa frontal (a 'Falha do Fundão' - segmento N-S) e rampas oblíquas (a ZCC, com direção NE-SW e 'Falha do Fundão' - segmento NW-SE), todas articuladas a uma falha mestra. 

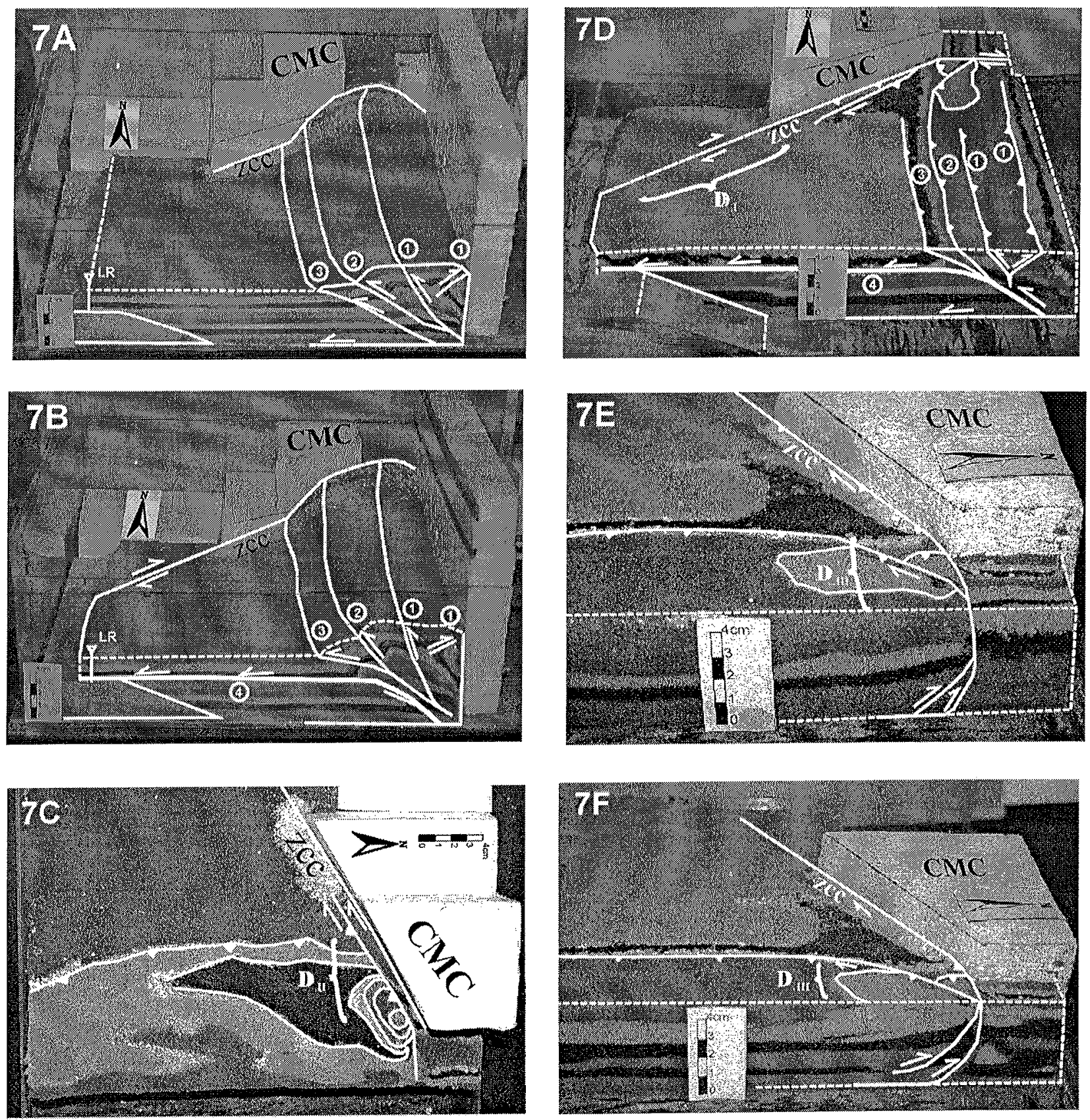

Figura 7 - Fotografias do experimento ZCC-III, que simula a deformação em duas fases tectônicas, com encurtamento total de $16 \%$ (6 cm) no domínio norte e de $21 \%(8 \mathrm{~cm})$ no domínio sul. A-Modelo após o encurtamento total no domínio norte e de $10 \%(4 \mathrm{~cm})$ no domínio sul, mostrando a ejeção de material na zona de transição e o sistema de falhas de empurrão no perfil sul. Observar; também, os traços das falhas, retilíneas, em planta. Uma linha de referência (LR), no antepaís do perfil, coincide com a terminação da coluna de areia. $B$-Modelo após o encurtamento total nos dois domínios, norte e sul, revelando no per-

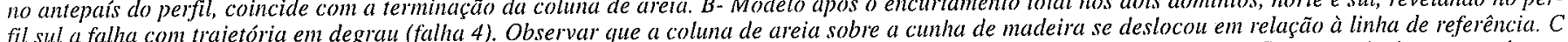
e D. Cortes horizontais no modelo, a 3 e $4 \mathrm{~cm}$, respectivamente, abaixo da altura máxima da cunha de areia, de $9 \mathrm{~cm}$. E e F. Cortes verticais, norte-sul, com espaçamento de $1 \mathrm{~cm}$, mostrando falhas de empurrão com vergência para norte. $D_{l}, D_{l l}$ e $D_{I I}$ - domínios estruturais (explicaçäo no texto).

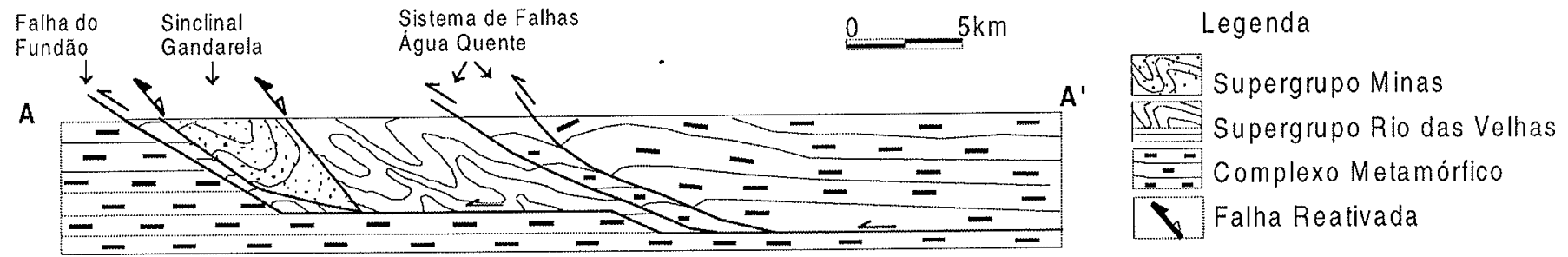

Figura 8. Perfil interpretativo da configuração estrutural do SCFC propostos a partir do modelo experimental ZCC-III. Notar no perfil, as estruturas (preexistentes) que podem ter influenciado a geometria do sistema de falhas de empurrão (a extremidade sudoeste do Sinclinal da Gandarela e dobras do Supergrupo Rio das Velhas). 
Assim apenas o SFAQ, caracterizado em planta por um traçado levemente sinuoso (Fig. 1), representaria o sistema oroclinal clássico. A geometria fortemente curva (quase triangular) do SCFC, em planta, é interpretado, com base no modelo ZCC-III, como resultante da presença de obstáculos nos domínios laterais do antepaís, somado ao efeito de uma forte restrição ao avanço livre sobre a falha mestra, em profundidade. Desta maneira, o conjunto de sistemas de falhas, do leste do $\mathrm{QF}$, poderia ser considerado um sistema oroclinal modificado.

A aparente incoerência entre o número de falhas que compõe o sistema oroclinal nos modelos e no SFAQ, no mapa geológico, resulta de uma das condições de contorno imposta aos experimentos. Esta diz respeito à espessura da coluna de areia. Trabalhou-se com uma coluna de areia representando $5 \mathrm{~km}$ de espessura, com a preocupação de melhor atender à simulação de uma tectônica pelicular delgada. Conforme demonstrado por Marshak \& Wilkerson (1992) e Huiqi et al. (1992) o número de falhas formadas por compressão, em modelos físicos de areia, depende da espessura do pacote: quanto menor a espessura, maior o número de falhas. Portanto, uma simples mudança na espessura do pacote de areia, será suficiente para simular o número real de falhas que compõe o SFAQ.

CONCLUSÕES Apesar de se simular no presente trabalho uma tectônica simplificada da inversão brasiliana, os experimentos físicos demonstraram que a configuração estrutural do SCFC e em particular da ZCC só se explica sob condições de contorno especiais.

As modelagens sugerem que a tectônica compressiva que afetou o leste do QF, no brasiliano, gerou um sistema oroclinal modificado. O sistema oroclinal clássico estaria representado pelo conjunto de falhas que compõe o SFAQ conectado, em profundidade, a uma grande falha com trajetória em degrau e rampas laterais, o SCFC.
Os modelos físicos demonstram que o mecanismo de formação de um sistema oroclinal pode sofrer modificações durante o seu desenvolvimento. Este fato acontece quando aumenta o coeficiente de atrito basal sobre a falha mestra ou quando ocorrem estruturas preexistentes, no antepaís, e a translação da lasca de empurrão, ativa, é transferida para outro horizonte, no interior do pacote. No QF, é possível que o inventário estrutural preexistente, da Bacia Minas, tenha influenciado a geometria do SCFC.

A ZCC representaria, no sistema oroclinal modificado, um sistema de falhas de rasgamento com feições transpressivas. Em função das diferentes propriedades mecânicas entre o bloco rígido do $\mathrm{CMC}$ e o material analógico que representa as supracrustais, produziu-se em todos os modelos uma deformação heterogênea na ZCC.

O sistema de falhas direcionais com componente oblíqua que compõe a ZCC na borda sul (domínio sudoeste) do CMC, pode ser classificado como uma zona de transpressão dominada por cisalhamento simples. A forte ascensão de material, na extremidade nordeste, mostrado em detalhe no modelo ZCC-III (e no modelo ZCC-IIb, figura 6A), ocorre quando a frente de deformação se aproxima do bloco rígido do CMC e caracteriza uma transpressão dominada por cisalhamento puro. Esta deformação justificaria, em um regime mais plástico, o forte fechamento do Sinclinal da Gandarela na sua porção norte, que nitidamente contrasta com a geometria da dobra em seu domínio central e sul (Fig. 1).

Agradecimentos À Fapemig, pelo auxílio financeiro (processo: CEX 908/95) e pela cessão de uma bolsa de Iniciação Científica (processo: CEX 2637/97), ao CNPq pelas bolsas de produtividade (processos no. 300487/89-4 e 302148/83-3) e a dois revisores anônimos da RBG pelas sugestões e críticas ao original.

\section{Referências}

Alkmim FF. Quade H., Evangelista M.T.R. 1988. Sobre a história da deformação dos metassedintentos do Supergrupo Minas e Grupo Itacolomi no Quadritátero Ferrífero (inédito)

Alkmim F.F. \& Marschak S. 1998. Transamazonian Orogeny in the Southern São Francisco Craton Region, Minas Gerais, Brazil: evidence for Paleoproterozoic collisin and collapse in the Quadrilátero Ferrífero. Precambrian Research, 90:29-58.

Carey S.W. 1955. The orocline concept in geotectonics. Paper Proceedings Royal Societ Tasmania, 89:255 - 289.

Carneiro M.A. 1992. O Complexo Metamórfico Bonfin Setentrional (Quadrilátero Ferrí fero, Minas Gerais): litoestratigrafia e evolução geológica de um segmento de crosta continenfal do Arqueano: Inst. Geociências, Universidade de São Paulo, São Paulo, Tese de Doutoramento, $225 \mathrm{p}$.

Chemale Jr. F Rosière C.A., Endo I. 1991. Evolução tectônica do Quadrilátero Ferrífero, Minas Gerais - Um modelo. Pesquisas, 18:104 - 127

Costa A.F. 1992. Estudo microestrutural das rochas do Complexo Granito-Gnaissico de Caeté, na região do contato com o Grupo Nova Lima, Quadrilátero Ferrífero

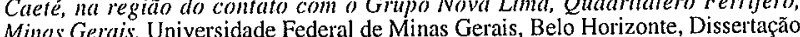
Minas Gerais. Universiado, $121 \mathrm{p}$.

Crocco Rodrigues F.A., Costa A.F., Souza R.A.C., Rosière C.A. 1989. Sistema de cavalgamento do nordeste do Quadrilátero Ferrífero - MG. In: SBG, Simpósio de Geologia de Minas Gerais, 5, Belo Horizonte, Boletim, 10:6 - 10 .

Dorr J.V.N. 1969. Physiographic, stratigraphic and structural development of the Quadrilátero Ferrifero, Brazil. U. S. Geological Survey Professional Pape; 641 (A):110 p. Washington

Endo I. 1988. Análise estrutural qualitativa ws minério de ferro e encaixantes, na Mina de Timbopeba - borda leste do Quadilatero Ferrifero, Mariana - $M G$. Universidade Federal de Ouro Preto, Ouro Preto, Dissertação de Mestrado, $130 \mathrm{p}$

Endo 1. \& Alkmim FF 1992. Geometria e cinemática da Zona de Cisalhamento Dúctil do Fundão na regiño da Mina de Timbopeba - borda leste do Quadrilátero Ferrífero. In: SBG, Simpósio de Geologia de Minas Gerais, 6, Ouro Preto, Anais, 28 - 31.

Endo I \& Fonseca M.A. 1992. Sistema de Cisalhamento Fundão - Cambotas no Quadrilátero Ferŕfero - MG: geometria e cinemática. In: SBG, Simpósio de Geologia de tero Ferrífero - MG: geometria e cinemática.
Minas Gerais, 6, Ouro Preto, Anais, $29-31$.

Endo 1. 1997. Regimes tectônicos do Arqueano e Proterozóico no interior da Placa Sanfranciscana: Quadrilátero Ferrifero e areas adjacentes, $M G$, Brasil. Inst. de Geociências, Universidade de São Paulo, São Paulo, Tese de Doutoramento, 221 p.

Fonseca M.A. 1990. O Sinclinal de Ouro Fino: análise descritiva e cinemática de um se mento do Sistema Fundāo, Quadrilátero Ferrífero, Minas Gerais. Universidade Federal de Ouro Preto, Ouro Preto, Dissertação de Mestrado, 120 p.

Fonseca M.A.\& Alkmim F.F. 1992. O Sinclinal de Ouro Fino e sua relação genética ao Sistema Fundão Quadrilátero Ferrífero - MG. In: SBG, Simpósio de Geologia de Minas Gerais, 6, Ouro Preto, Anais, 66-67.

Fossen $\mathrm{H}$. Tikoff $\mathrm{B}$. Teyssier $\mathrm{C}$ 1994. Strain modeling of transpressional and transtensional deformation. Norsk Geologisk Tidsskrift, 74:134-145.

Gomes C.J.S., Ferreira J.E., Pereira Filho M. 1999. Modelos físicos de falhas de empurrão com trajetória em degrau. Rev. Bras: Geociências 29 (4):539-548.

Gomes C J \& Ferreira JE 2000 Geometry and kinematics of experimental antiformal stacks. An. Acad. Bras. Ciências, 72 (2):195-217.

Hashizume B.K. 1998. Texturas e microestruturas do minério de ferro da Mina de Brucutu $N E$ do Sinclinal de Gandarela $(M G)$. Universidade Federal de Minas Gerais, Belo Horizonte, Dissertação de Mestrado, $133 \mathrm{p}$.

Hubbert M.K. 1937. Theory of scale models as applied to the study of geologic structures. Geological Society American Bulletin, 48:1459-1520.
Huiqi L., McClay K.R., Powell, D. 1992. Physical models of thrust wedges. In McClay, Chapman \& Hall (eds.). Thrust Tectonics: London, 71-81.

Macedo J.M. 1997. Models of Continental Fold-Thrust belt Salients. University of Illinois at Urbana-Champaign, Illinois, Tese de Doutoramento, $294 \mathrm{p}$.

Machado N., Noce C.M., Oliveira, O.A.B., Ladeira E.A. 1989. Evolução geológica do Quadrilátero Ferrífero no Arqueano e Proterozóico Inferior, com base en geocronologia U-Pb. In: SBG, Simpósio de Geologia de Minas Gerais, 5, Belo Horizonte, Anais, $1-5$

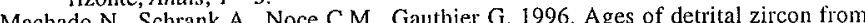
Ar., Sean-Paleoproterozoic sequences: Implications for Greenstone Belt setting and Archear-Paleoprous Brazil. Eath and Planetary Sciences Letters, 141:259-276.

Marshak S. 1988. Kinematics of orocline and arc formation in thin-skinned orogens. Tectonics, 7:73-86

Marshak S. \& Wilkerson M.S. 1992. Effect of overburden thickness on thrust belt geometry and development. Tectonics, 11:560-566.

Marshak S., Wilkerson M.S., Hsui A.T. 1992. Generation of curved fold-thrust belts: Insight from simple physical and analytical models. In McClay; Chapman \& Hall (eds.) Thrust Tectomics. London, $83-92$

Marshak S. \& Flottmann T. 1996. Structure and origin of the Fleurieu and Nackara Arcs in the Adelaide fold thrust belt, South Australia: salient and recess development in the Delamerian Orogen. J. Struct. Geology, 18:891-908.

McClay K R \& Ellis P G. 1987 a. Analogue models of extensional fault geometries. In M.P. Coward J F Dewey Hancock (eds.) Continental Extensional Tectonics Geological Society of London - Special Publication, 28:109-125.

McClay K R. \& Ellis P.G. $1987 \mathrm{~b}$. Geometries of extensional fault systems developed in model experiments. Geology, 15:341-344.

Mulugeta G. \& Koyi H.1987. Three-dimensional geometry and kinematics of experimental piggyback thrusting. Geology, 15:1052-1056

Rosière C.A. \& Noce C.M. 1987. Zonas de cisalhamento no Sinclinal de Gandarela, Qua drilátero Ferrífero, MG. In: SBG, Simpósio Nacional de Estudos Tectônicos, 1, Salvador, Anais.

Rosière C.A., Noce C.M., Ladeira E.A. 1987. Geologia Estrutural da extremidade sul do Sinclinal do Gandarela. In: SBG, Simpósio de Geologia de Minas Gerais, 4, Belo Horizonte, Anais 7:254 - 268.

Rosièr C A Chemale Jr. F Crocco Rodrigues F.A. 1991. Geologia Estrutural do Sinclinal da Gandarela. In: SBG, Simpósio Nacional de Estudos Tectônicos, 3, Rio Claro, Anais, $14-16$

Rubey W.W. \& Hubbert M.K. 1959. Role of fluid pressure in mechanics of overthrust faulting. Geol. Soc. Am. Bull., 70:167-206

Smith R.E. \& Wiltschko D.V. 1996. Generation and maintenance of abnormal fluid pressures beneath a ramping thrust sheet: isotropic permeability experiments. J. Struct Geology, 18:951-970.

Vendeville B., Cobbold P.R., Davy P., Brun J.P., Choukroune P. 1987. Physical models of extensional tectonics at various scales. In M.P. Coward, J.F. Dewey \& Hancock (eds.) Continental Extensional Tectonics, Geological Society of London, Special Publication, 28:95-107.

Manuscrito A-1101

Recebido em 25 de junho 1999

Revisão dos autores em 25 defevereiro de 2000 Revisão aceita em 10 de março de 2000 